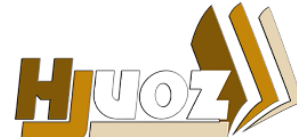

hjuoz.uoz.edu.krd p-ISSN: 2410-7557 e-ISSN: $2518-5128$
كَّوارا زانستيّن مروّقايهتى يا زانكوّيا زاخوّ

مجلة العلوم الانسانية لجامعة زاخو

Humanities Journal of University of Zakho (HJUOZ)

Vol. 5, No. 3, pp. 687-694, Sept.-2017

\title{
اللصوص وقطاع الطرق واثرهم في تعطيل النشاطات الاقتصادية في مدن المشرق الاسلامي
}

\author{
طه خضر عبيد 1 و ادريس محمد حسن احمد² \\ "قسم التاريخ، كلية التربية للعلوم الانسانية، جامعة الموصل- العراق. \\ 2قسم التاريخ، كلية العلوم الانسانية، جامعة زاخو، اقليم كردستان العراق-العراق.
}

https://doi.org/10.26436/2017.5.3.442 2016/02 2016/04 تاريخ الاستلاميخ النشر: 201/09

الملخص:

تعد اعمال اللصوص وقطع الطرق من اقذر الاعمال التي حرمها الله سبحانه وتعالى، فقال في محكم التنزيل: ( والسارق والسارقة فاقطعوا ايديهما جزاءً بما كسبا نكالا من الله والله عزيز حكيم) ، وذلك لما لها من اثر سيء جدا في تعطيل الحياة الاقتصادية في المدن،

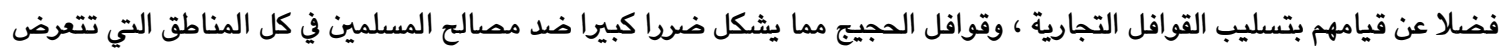
لمثل هذه الاعمال. ونتيجة لهذه الاعمال التخريبية تنقطع التجارة وتتكدس البضائع في مناطق وفرتها ولا تصدر الى المناطق التي

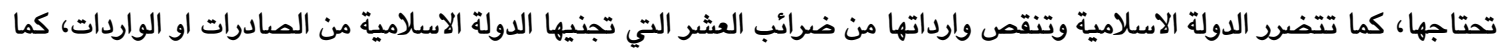
تتسبب اعمال اللصوصية في تدمير اقتصاد مدن القوافل ، التي يعتمد سكانها على التجارة، وبالتالي نلاحظ اثرها المدمر على كل اقتصاد البلدان الاسلامية، لذا توجب على الدول الاسلامية اعداد الجيوش للقضاء على اللصوص وقطاع الطرق،لتامين الطرق من هذه

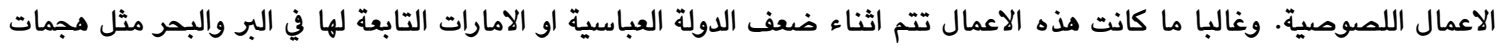
الاعراب على القوافل المختلفة وهجمات الزط او الميد في البحر الهندي،، ويستغل اللصوص وقطاع الطرق، الظروف السياسية التي تمر بها هذه الدولة ، وتنشط اعمال اللصوصية في حالة ضعف الدولة وتنتهي او تضمحل في اوقات قوة الدولة أو عظمتها. الكلمات الدالة: اللصوص وقطاع الطرق، تعطيل النشاطات الاقتصادية، المشرق الاسلامي، المدن الاسلامية.

وتقع اللوم على الدولة في الكثير من الاحيان وذلك نتيجة عدة اسباب منها على سبيل المثال لا الحصر ضعف مركز الخليفة ، وتحكم القوى

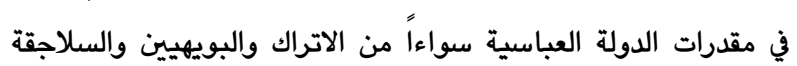
وغيرهم، وتستغل على أثرها اللصوص وقطاع الطرق حالة الفوضى والانقسام، فتنشط مجماتهم واعمالهم اللصوصية، فتؤثر على اقتصاد

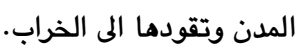

\section{2. اللصوص وقطاع الطرق}

تعرضت عدد من المناطق في المشرق الإسلامي إلى عمليات النهب والسلب والقتل والتخريب والحرق من قبل بعض الفئات أطلقت عليهم

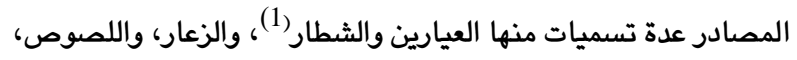
وقطاع الطرق، والرعاع ، والسفلة، والسوقة، والأحداث، والحرافيش،

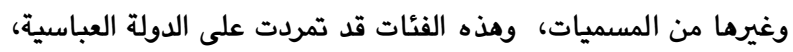
ونشطت حركاتهم وتنظيماتهم، وخاصة بعد الضعف الذي أصاب

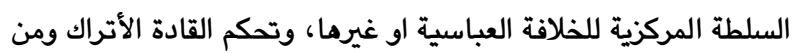
بعدهم البويهيين ثم السلاجقة في مجريات الأمور السياسية والعسكرية

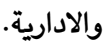

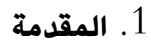

تعد موضوع اللصوص وقطاع الطرق وأثرهم في تعطيل النشاطات الاقتصادية في مدن المشرق الإسلامي من المواضيع المهمة في حقبة الدراسة لما لها من أثر سيء على ثل نمو وتطوير الحياة الاقتصادية في المدن والارياف، وتؤثر تلك الاعمال سلباً على الحياة الاقتصادية والاجتماعية، فتشل الحياة الاقتصادية نتيجة قيامهم بأعمال الحرق في الاسواق والمحلات التجارية، فضلاً عن اعمال النهب والسلب والقتل ويخاصة نهب القوافل التجارية وقوافل الحجيج، من قبل العياريين والشطار، والقبائل البدوية، علاوة عن مجمات القرامطة وقطعهم الطرق على القوافل التجارية وقوافل الحجاج، فتؤدي تلك الاعمالالى حدوث اضرار كبيراً جدا ضد مصالح الدولة حكومتا وشعباً، ولا سيما طبقة وهي

التجار والميسورين منهم. وتنقطع التجارة وتتكدس البضائع والسلع في المدن التي تعرضت للاعمال التخريبية من اللصوص وقطاع الطرق، وتنتج عنها تدمير اقتصاد مدن القوافل، لاعتماد سكانها بالدرجة الاساس على التجارة، ويذلك تفقد تلك المدن اهميتها التجارية وتضمحل دورها في المجالات الاقتصادية والاجتماعية والسياسية. 
الصولي إلى هذه الحالة بقوله : " وكثرت المتلصصة ببغداد وكبست دور المياسير، وخرج الناس عن بغداد هاربين إلى كل وجه، على انسداد

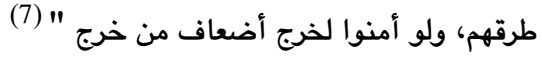
أما عن وجود العيارين في بلاد ما وراء النهر فقد كانوا يمثلون كتلة كبيرة، وقد استعان بهم الأمراء السامانيون في كثير من الأحيان للمواجهات العسكرية ضد أعدائهم (8)، وفي السياق ذاته يشير النرثخي الى وجود هؤلاء في بلاد ما وراء النهر، حيث يذكر أسماء ثلاثة من قادة العيارين وهم كل من ( حشري ) و ( باغي )، و ( كردك ) ووصفهم

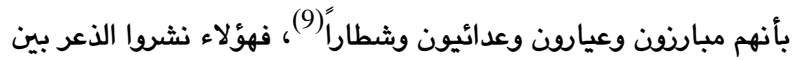
الأهالي حتى أصبحت الطرق غير آمنة، كما أصبح الناس غير آمنين

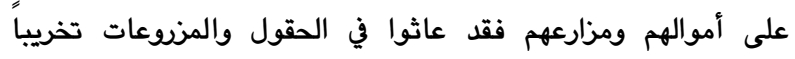
وفسادا(10). وتفاقم خطر العيارين وازداد نشاطهم، وصارت أسواق بغداد تتعرض لحرائق مدمرة بين آونة وأخرى، التهمت النيران الكثير من الدكاكين وما

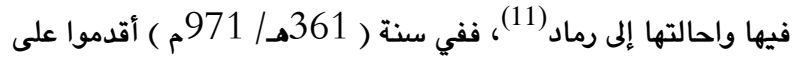
نهب أموال الناس، وأحدثوا الأعمال الشنيعة من القتل والتخريب واحراق الدود في بغداد، ومن جملة ما احترق محلة الكرخ التي كانت

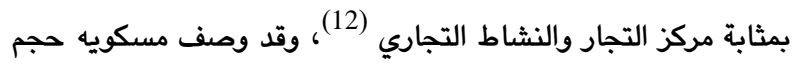

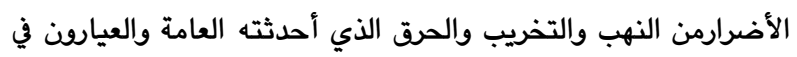
بغداد بقوله : " ...، وزادت العامة،...، من حالها في الإغارة والاقدام على النهب والحرق وأسرفت في ذلك حتى بطلت الأسواق وانقطعت المعايش وتعذر على أكثر الناس الوصول إلى ماء دجلة حتى شريوا ماء الآبار،...، وركب الوزير أبو الفضل بنفسه لقتال العيارين وواقعهم فلم يقدر عليهم " (13) وواصل العيارون مجماتهم على العاصمة بغداد في سنة ( 362هـ/ 972م )، استغلوا ضعف السلطة البويهية، وعدم قدرتها على ضربهم بقوة، فقد استولى العيارن والشطار على بغداد وكبسوا الدور، وتعرضوا للحريم، حتى أصبح هؤلاء سادة الموقف في شوارع وطرقات ومحال بغداد، وغاب الامن وغاب القانون عنهم ، مما اضطر الأمير البويهي عز الدولة بختيار بن ركن الدولة إلى القدوم إلى بغداد من أجل السيطرة على

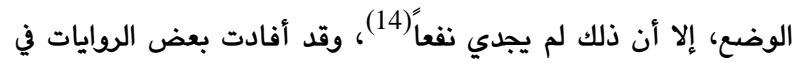
المصادر إلى حالة التدهور في بغداد فاضطرت السلطات إلى القاء النار في الجانب الغربي من بغداد ، مما تسبب في إحتراق مساحات واسعة من الكرخ، ومنع السلطات الناس من القيام بإطفاء الحرائق، فقد أشارأبو

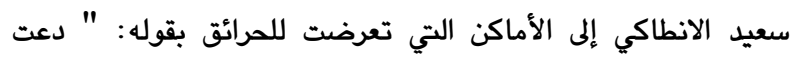

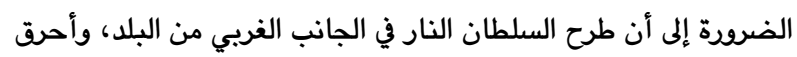
باب البصرة وما يليه من حد بركة زلزل إلى السماكين، ومنع الناس من إطفائها، وأخذت يميناً وشمالاً....، وانتقل الناس من الجانب الغربي من المدينة إلى الجانب الشرقي منها " (15). ومن الروايات الأخرى أن وأن الوزير ابي الفضل الشيرازي، أرسل الحاجب لمساعدة صاحب الشرطة
إلا أن من أبرز تلك الفئات الاجتماعية ما أطلقت عليهم المصادر بالعيارين والشطار، ويدخل ضمن هذه المجموعة أهل الصنايع وياعة الطرق وأهل السوق، فكانت حركتهم موجهة بشكل أساسي ضد الطبقة الثرية والتجارفي الأسواق، وضد السلطة وممثليها (2). ويرجع ظهور هذه الطبقة أثناء الفتنة بين الخليفة الأمين وأخيه المأمون من خلال حصار جيش المأمون لمدينة بغداد، فقد استنجد الخليفة الأمين بهؤلاء للدفاع عن العاصمة، بعد أن عجز جنوده في الدفاع عنها،

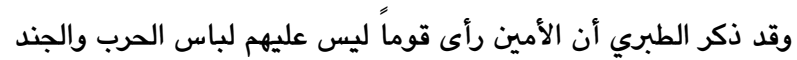

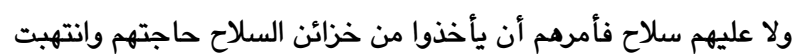

الغوغاء سلاحاً كثيراً (3).

وعلى مرالأيام كثرت أعدادهم وانقسموا إلى فئتين فئة حاقدة ذات نزعة أنانية ودموية وفئة متمردة تهدف الى اصلاح الامود وفق افكارها التي تنطوي على فعل الخير، وساعدت الظرف لبروزهم المتمثلة بضعف السلطة وكثرة الاضطرابات، ومذا ما نلاحظه في المشرق الإسلامي الغارق في النزاعات السياسية، حيث ما أن تضعف قبضة السلطة،

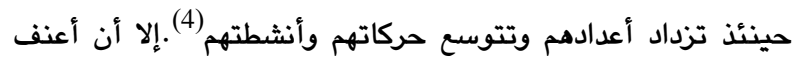
الهجمات من قبل العيارين والشطار على مدن المشرق الإسلامي تعرض الأسواق للنهب والحرق، وتحكمهم في أرباب التجارة بفرض ضرن فرائب معينة ونهب وحرق دور الميسورين، وما صاحب ذلك من أعمال القتل والحرق، وتشير هذه الاعمال دون شك إلى دخول عناصر دخيلة غير منظمة في حركة العيارين واستغلالها مبادئهم من أجل مصلحتهم الشخصية في النهب والسلب والدمار الغير المشروع ، مما تسبب في نشر الفوضى وأعاق التطور والنمو التجاري والصناعي والحضاري، مما دعا بعض المؤرخين إلى نعت الحركة باللصوصية والأعمال التخريبية والذي

يمثل الوجه الثاني لتلك الحركة(5). وعلى الرغم مما قيل عن العيارين والشطار وكثرة حركاتهم ، فهناك نماذج من الأمثلة في المصادر تبين ما أحدثته هذه الحركة من أعمال

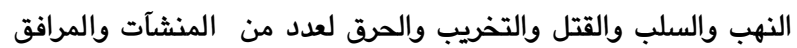
العمرانية في مدن المشرق الإسلامي، وخاصة في العراق وفي مدينة بغداد بالذات ، فجاءت أولى الإثارات عن مجماتهم في المصادر من خلال فترة

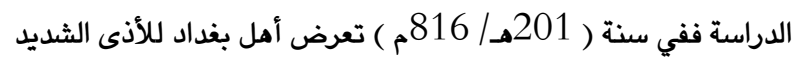
من قبل الشطار والفساق الذين أقدمواعلى قطع الطريق، فأخذوا يخطفون الناس وخصوصاً الاطفال والنساء، ويجبون الضرائب من المارة في الطرق المؤدية إلى بغداد، وينهبون القرى المحيطة بها مكابرة، ولا سلطة عليهم من السلطان ولا رادع لهم، ووقع الناس من جراء أعمالهم في بلاء عظيم (6). وقد ازدادت اعداد اللصوص في بغداد واستغلوا من خلالها ضعف السلطة وشكلوا خطراً على أمنها وأخذوا يكبسون الدور ويخاصة الميسورين

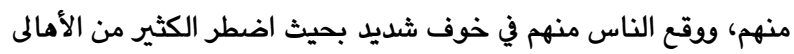
إلى مغادرة مدينتهم وذلك في سنة ( 331 
أرضها انتصاف النهار في الوقت الذي جرت العادة بازدحام الناس فيه بهذا المكان " (23). ويعد ان زادت ضراوة ونشاط العيارين في بغداد سنة ( 417هــان 1026م) فوصلت لهذا الغرض فرقة من الجند ( الاصفهلارية ) لحفظ الأمن فيها وقمع نشاط العيارين، وكتبوا إليهم بالانصراف عن بغداد، مرهن غير أن العيارين لم يلتفتوا لمطالبهم ، بل خرجوا بأنفسهم إلى معسكر الجند يصيحون عليهم بعبارات السب والشتم، فوقع القتال بينهم، وأدى ذلك بقيام الجند الهجوم على محلة الكرخ أكبر الأسواق التجارية في بغداد ، وأضرموا النار في المحال التجارية والأسواق، وأحرقوا الدود الذي احتمى فيها العيارون فاحترقت نتيجة لذلك الكثير من المحال والدور، ومن جملة ما احترق سوق الدقاقين ، وامتدت الحرائق إلى سوق

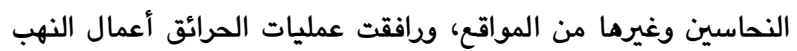
والسلب على نطاق واسع (24). ويلاحظ من خلال تلك الأحداث أن الجند والعامة والعيارين كانوا مشتركين في القيام بأعمال التخريب والحرائق، والسلب والنهب على

حد سواء.

وتواصلتهجمات وكبسات العيارين وازدادت قوتهم وسطوتهم ففي سنة

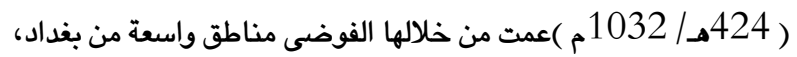
واحترقت من جرائها الكثير من الأماكن والأسواق والمساجد، ورافقتها أعمال النهب ومن جملة ما نهب درب عون وأخذت أبوابه، ونهب أيضاً درب القراطيس والفروع التي تؤدي إليه(25). وأستمرت الفوضى الهم والفساد في بغداد ففي سنة ( 426هـ/ 1034م ) واصل العيارون عملهم ليلاً ونهارًا ، فعم الفساد ومنع السقاؤون من حمل الماء إلى بعض

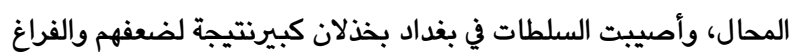
السياسي والأمني فاستغل العيارن تلك الظروف لصالحهم فسيطروا على بغداد، وملكوا الجانبين ولم يبق للخليفة ولا للسلطان جلال الدولة البويهي أي حكم، فقاموا بأشعال الحرائق في الأسواق والمحلات ، مع ومع ولات القيام بأعمال السلب والنهب وغيرها من الأفعال الشنيعة المنافية للشرع (26) واشتدت شوكة العيارين سنة ( 441هـ/ 1049م ) في وفي السمال الجانب الغربي من بغداد، حتى اضطر الكثير من الناس إلى ترك منازلهم والانتقال إلى القسم الشمالي من الجانب الغربي ( منطقة الحريم ) فاشتروا الخرابات وعمروها (27). وكان العيارين والشطار يستغلون حالة أضطراب الأمن في بغداد، فعندما حاصر السلطان السلجوقي محمد بن محمود مدينة بغداد في سنة

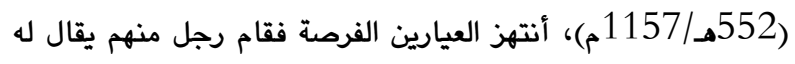
أبو الحسين العيار، وأخذ معه جماعة من الرجال، ومعهم الشطار، ونزلوا

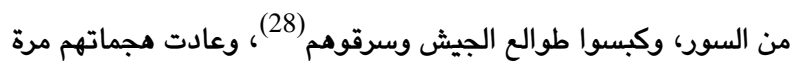

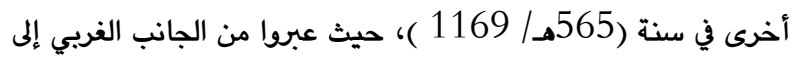
الجانب الشرقي، فقاموا بأعمال التخريب والنهب، وأخذوا أموال الحجاج والأغنياء والميسورين(29) .
في التهدئة، ولما كان هذا الحاجب مبغضاً لأهل الكرخ، لذا أمر بالقاء النار في سوق النحاسين لتمتد بعد ذلك إلى المناطق الأخرى من الكرخ (16). وعلى الرغم من المبالغة في حجم الخراب والحرائق والقتل والنهب التي تعرضت لها مدينة الكرخ، إلا أن ذلك لايعني عدم تعرضها لمثل تلك الأعمال، فقد وصف ابن الأثير حجم الخسائر المادية والبشرية لهذه الفتنة بقوله : " وكان عدة من احترق فيه سبعة عشر ألف إنسان، وثلاثمائة دكّان، وكثير من الدُود، وثلاثة وثلاثين مسجداً، ومن الأموال

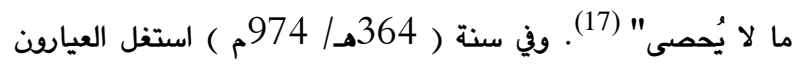
الصراع الدائر داخل أجهزة الدولة لدواعي مذهبية وطائفية، وأدى ذلك إلى ان زادت ضراوة العيارين وانتشر الفساد والتخريب والقتل والنهب، واستهدف العيارون التجار، وقاموا باشعال الحرائق في مدينة الكرخ (18)، فاحتق من جراء ذلك سوق الخشابين، ثم توسعت الحرائق لتشمل سوق الجزارين واصحاب الحصر ( الحصران )، وأحرقوا سوق باب الشعير ونهبوا الكثير من الأموال، ونجم عن تلك الاحداث خسائر فادحة، ولم يقف نشاط العيارين عند هذا الحد ، فقد كانوا يركبون الدواب ويسيطروا على الأمور، وأخذوا الخفائر عن الاسواق والدروب ، وظهر هاري

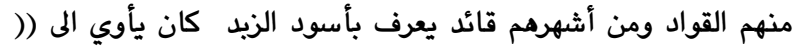

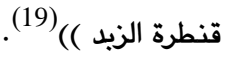
واشتدت الفتنة في بغداد سنة ( 380هـ/ 990 م ) ) بين أهل باب البصرة

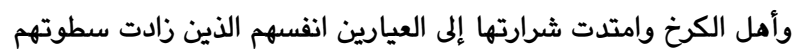
في جانبي بغداد، وصار لكل فريق منهم أمير وفي كل محلة مقدم ، فلقي منهم الناس الأذى الكثير، ووصل الأمر إلى حد أن حدثت الفتنة بين العيارين ، وقاموا بإحراق محال بعضهم البعض، واحترقت دور كبار

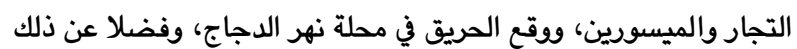
فقد تعرضت الأسواق إلى النهب، واستمر الفساد والفوضى لحين عودة الأمير البويهي بهاء الدولة إلى بغداد (20).

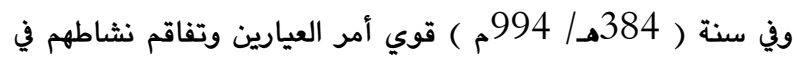
بغداد، وقادهم زعيم يدعى عزيز البابصري من أهل باب البصرة، والتف

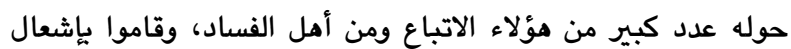
النيران في المحال والدروب، ونهبوا الأموال، وفرضوا الضرائب على

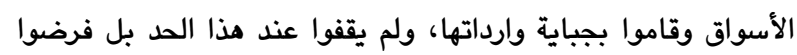

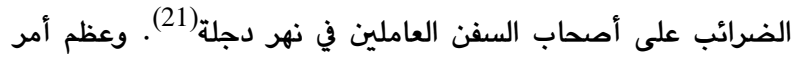
العيارين على اهل بغداد في سنة ( 392 هـ/ 1001م ) وعاش الناس اهل في خوف شديد فخربت البلاد من جراء أعمالهم، مما أضطر الكثير من العامة في بغداد بالانتقال إلى خارج المدينة فمنهم من ذهب إلى البطيحة، ومنهم من اعتصم بباب الأزج، في حين ذهب آخرون إلى عكبرا والانبار(22)، وقد وصف لنا الصابي في تاريخه ما جرى في هذه السنة بقوله : " ولقد حدثني جماعة من الناس أنهم شاهدوا صينية الكرخ - وماري فيما بين طرف الحذائين والبزازين - والفواخت والعصافير تمشي على بلى 
في أيام خلافة المأمون، استغلوا من خلالها الفتنة التي حدثت بين الخليفة الأمين وأخيه المأمون، فعاثوا وأفسدوا وذلك بقيامهم بالأعتداء على القوافل التجارية وقطعوا طريق البصرة، وسلبوا الكثير من الأموال والسلع، فأرسل الخليفة المأمون عدة حملات ضدهم غيرأنه لم يستطع القضاء عليهم ، بل أن خطرهم على الدولة العباسية قد ازداد، فسيطروا على طريق البصرة وفرضوا المكوس على السفن الداخلة إلى بغداد ، وحالوا دون وصول الأقوات والمؤن إلى بغداد، وقد تزعمه رجل يقال له محمد بن عثمان وقام بأمره رجل آخر اسمه سماق، واستمر خطرهم حتى تمكن القائد عجيف بن عنبسة في عهد خلافة المعتصم بالله بالقضاء على ثورتهم (37). ويلاحظ من أفعالهم أن مستواهم المعاشي في في

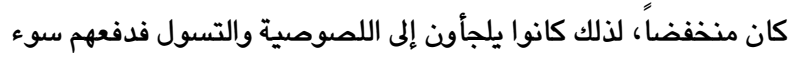
الوضع الاقتصادي إلى التذمر(38). وتولى حكم مدينة حمص خلف بن ملاعب الكلابي، وقد كان رجاله وأصحابه قطاع الطرق، يمارسون هذه الأعمال فقد قطعوا الطريق على الناس، ووقع على الناس منهم ضرد كبي، ولأجل ذلك سار إليهم صاحب دمشق تتش بن ألب أرسلان وتمكن من أخذ حمص منهم وكان

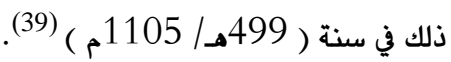
ويشير أسامة بن منقذ إلى وجود عصابات ولصوص أقدموا على قطع الطريق في تخوم بعلبك، وشيزر، ونابلس، وأحدثوا فيها الفساد والتخريب والنهب والسلب والقتل (40) وذكر ابن الأثير الخراب الذي لحق بمدينة نيسابور في سنة (أنهابت

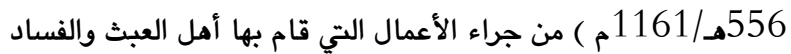
واللصوصية الذين أحدثوا فيها النهب والسلب وتخريب البيوت والمعالم العمرانية فيها، فقد أشار إلى حجم الخراب والدمار والنهب قائلاً : " وقتل من أهل الفساد جماعة، فخربت نيسابور بالكلية، ومن جملة ما

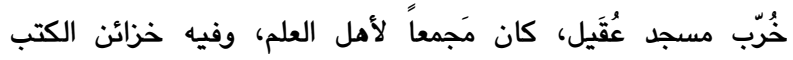
المرموقة، وكان من أعظم منافع نيسابور“ وخُرّب أيضاً من مدارس وفيه الحنفية ثماني مدارس، ومن مدارس الشافعية سبع عشرة مدرسة، وأحرق خمس خزائن للكتب، ونهب سبع خزائن كتب وبيعت بأبخس الأثمان، وهذا ما أمكن إحصاؤه سوى ما لم يَّكر " (41). يستنتج من خلال النص حجم الخراب والدمار والنهب والسلب الذي لحق بمدينة نيسابور، إلا أن هذه الرواية لا تخلوا من المبالغة في حجم الخراب الذي تعرضت لها هذه المدينة. يتبين من خلال ما سبق عظم ضرد هذه الاعمال العدوانية المتمثلة باللصوصية وقطع الطرق ، وما تركته من آثار سيئة على المناطق التي حدثت بهاهذه الاعمال ، فاضرت بالافراد والمؤسسات الادارية والعسكرية ، واضرت باقتصاد الدول التي حدثت فيها هذه الاعمال التخريبية.

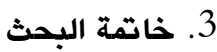

وزدادت مجمات العيارين والشطار في خلافة المستعصم بالله العباسي

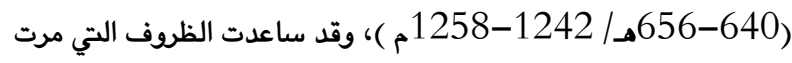
بها الدولة الإسلامية، العيارين والشطار واللصوص على زيادة نشاطاتهم، وذلك بسبب الفتنة بين العامة في بغداد، وظهور عصبيات المحلات بشكل كبير، وتدهور أقتصاد العراق، وازدياد الفوارق الاجتماعية بين مختلف شرائح المجتمع العراقي، وتعاقب ظهور الازمات الاقتصادية، فضلاً عن الخطر الخارجي المتمثل بالغزو المغولي، وعلاوة عن حدوث الكوارث الطبيعية في تلك الفترة، اضافة إلى ضعف شخصية الخليفة، وضعف الجهاز الإداري، كل ذلك أدى إلى أنتشار الفقر، وانخفاض المستوى المعاشي للفرد، فأستغل العيارين والشطار تلك الأوضاع المتدهورة لصالحهم (30)، وكثرت نشاطاتهم وحركاتهم، ومن

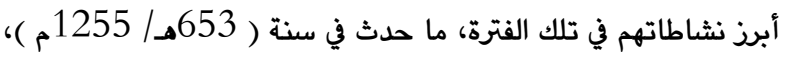
فقد كثر فساد العيارين في بغداد، فكانوا يسلبون عمائم الناس وياخذون

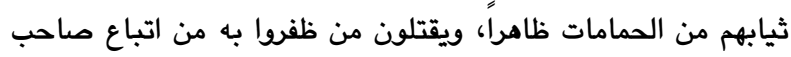
الشرطة، ونهبوا الأسواق، وصار الناس معهم في بلاء عظيم(31). ويلاحظ مما تقدم بأن العيارين والشطار مهما تعددت نياتهم، فقد أقدموا على الأعمال التخريبية وخصوصاُ اشعال الحرائق في المحلات والأسواق ودود التجار والميسورين، وما رافق ذلك من أعمال النهب والسلب، فاضطر الأهالي وخاصة طبقة التجار إلى ترك مناطقهم

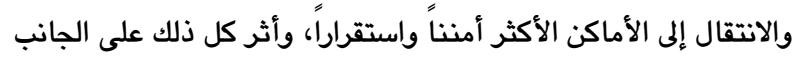
الاقتصادي للدولة الإسلامية، وشكلت لهذا الغرض الجيوش بالوقوف ضد الأعمال الشنيعة الذي يقدمون عليها. وقد ذكر بعض البلدانيين والرحالة المسلمين إثارات إلى عدد المناطق

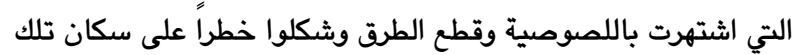
المناطق، فقد أشار ابن حوقل إلى مفازة خراسان وفارس وكرمان وأصفهان وقم وقاشان والري ، وتعد هذه المفازة من أكثر المفازات التي تقوم فيها أعمال اللصوصية وقطع الطرق والفساد، وكان هناك وهاك وهن ملجأ في تلك المفازة يعتصم بها اللصوص ، ويكون مأوى لهم يخفون

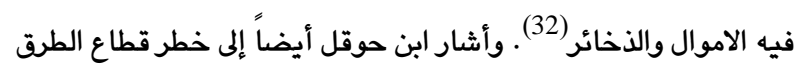
في منطقة جور(33) وفيها سبعة أجيال لكل جيل لهم رئيس خاص بهم وهم صنف من الأكراد وحيهم يبلغ تعداده حوالي عشرة آلاف رجل ممتنعين عن السلطان، ويقطعون الطريق ويخيفون السبيل في نواحي كرمان إلى مفازة سجستان وحدود فارس، وتمكن السلطان من كسر

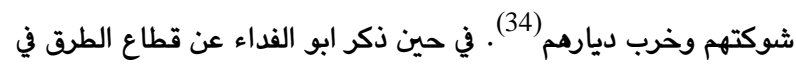

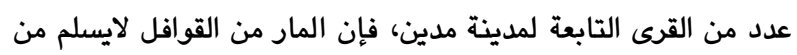
قطاع الطرق في هذه المناطق (35). وقد ذكرت عدد من المصادر الأعمال التي قام بها جنس يقال لهم الزط(36) فقد احترفوا السلب والنهب والإغارة وقطع الطريق، وقاموا بحركة في جنوب العراق بنواحي البصرة في سنة (219هـ/ 834م )، فتكاثروا في بطائح العراق وأخذوا يشنون الهجمات على الدولة العباسية 


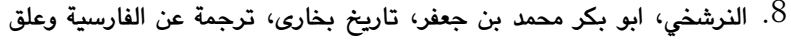

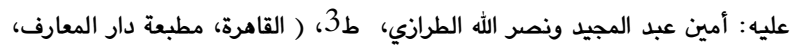

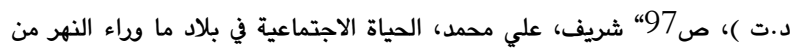

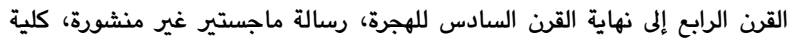

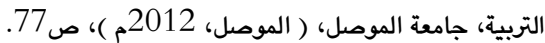

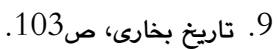

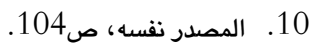

11. الكبيسي،حمدان عبد المجيد، أسواق بغداد حتى بداية العصر البويهي 1453- 1635-

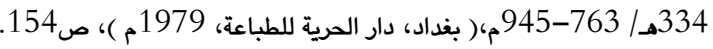

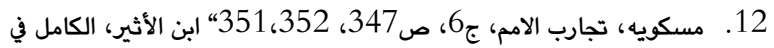

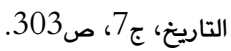

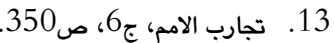
14. نوري، موفق سالم، اشكالية العلاقة بين العيارين والشطار والسلطة البويهية،

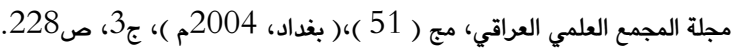

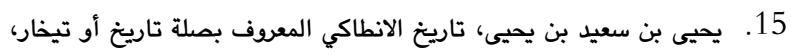

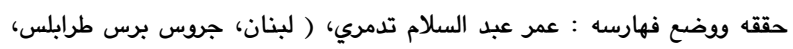

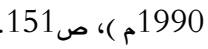

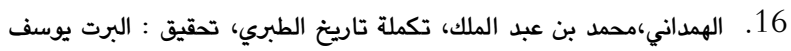

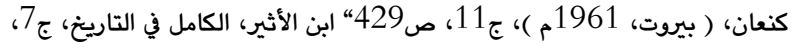

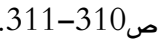
17. المصدر نفسه، ج7، ص311. ص.311.

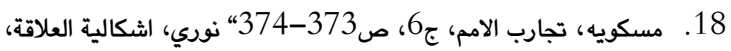
ص230. 19. ابن الجوزي، ابو الفرج عبد الرحمن بن علي بن محمد، المنتظم في تاريخ الامم

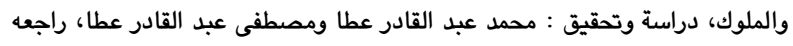

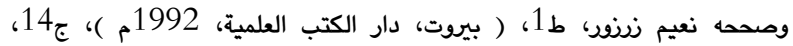
ص234-235" ابن كثير، الحافظ ابو الفداء اسماعيل القرشي الدمشقي، البداية

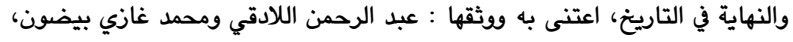

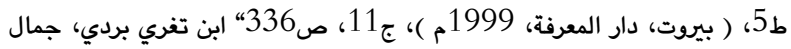

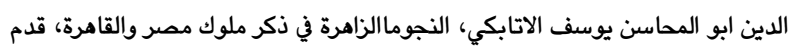
له وعلق عليه : محمد حسين شمس الدين، ط1، ( بيرت، دار الكتب العلمية،

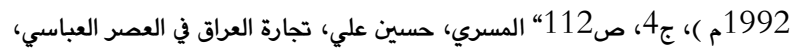

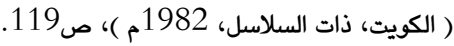

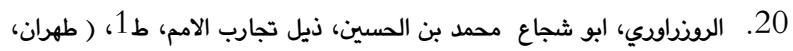

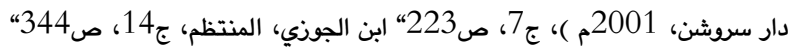

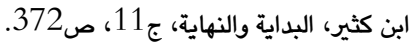

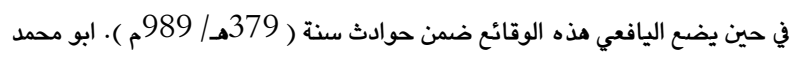

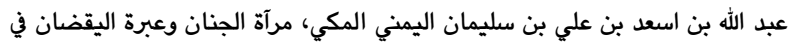

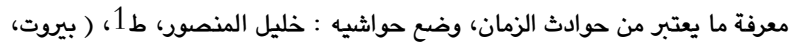

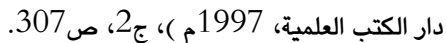

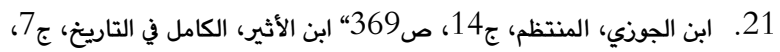

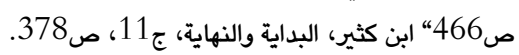

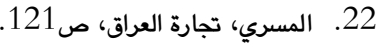

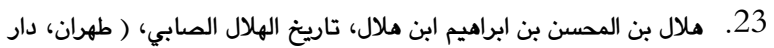

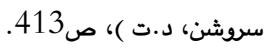

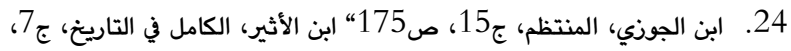

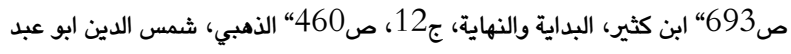

\section{توصل البحث الى عدد من النتائج مذها:} 1. ان ازدياد الاعمال اللصوصية وقطاع الطرق كون انعكاساً على ضعف الدولة،مما فسح المجال إلى كثرة نشاطات الحركات المعارضة للدولة، ويالتالي أدى الى انخفاض المستوى المعاشي للناس. 2. عطلت اعمال السرقة واللصوصية التجارة الداخلية والخارجية. 3. اضرت بالاقتصاد الاسلامي بشكل كبير، فاضرت الفرد والمجتمع وليه والدولة معاً.

4. عطلت اعمال اللصوصية قوافل الحجيج الى بيت الله الحرام. 5. شغلت هذه الاعمال الدولة الاسلامية بتوفير الجيوش ونفقاتها للقضاء على هذه الاعمال ،بدلا من ان توجه للدفاع عن حدود الدولة

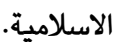
6. ادت هذه الاعمال الى اضطراب الاوضاع الداخلية في المدن والقصبات، فتسببت بحرق الاسواق وتعطيل النشاطات الاقتصادية في المدن الاسلامية ونالت مدينة بغداد النصيب الاكبرمن التخريب بفعل الاعمال الذي اقدم عليها العيارين والشطار.

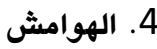

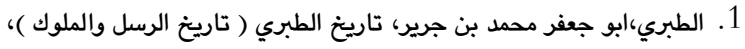

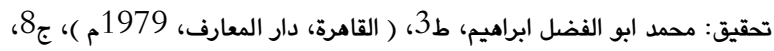

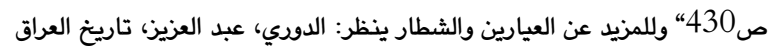
الاقتصادي في القرن الرابع الهجري، ط4، ول ( بيروت، مركز دراسات الوحدة العربية،

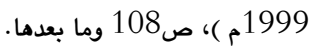
2. عارف، رفاه تقي الدين، العامة في بغداد في العصر العباسي الأول والثاني (

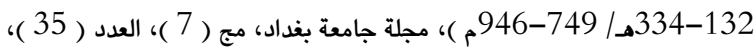

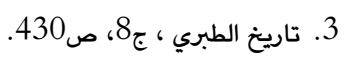

4. للمزيد عن حركة العيارين والشطار ينظر: النجار، محمد رجب، الشب، الشطار

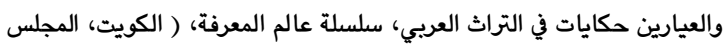

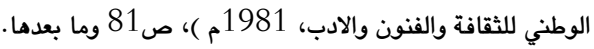

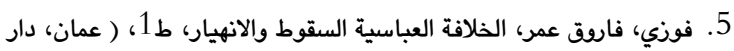

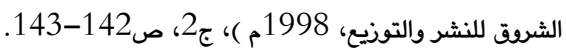

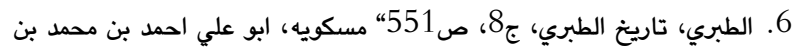

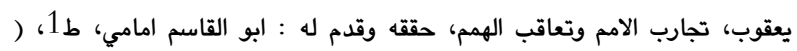

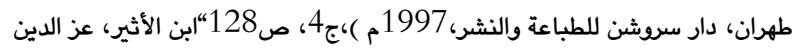

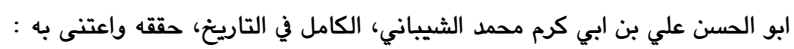

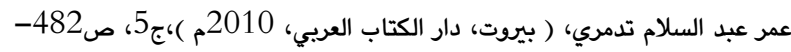

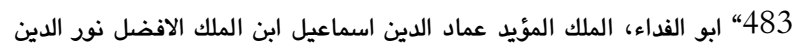

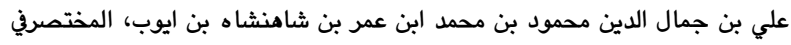

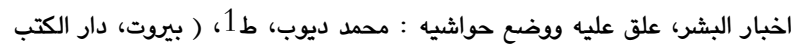

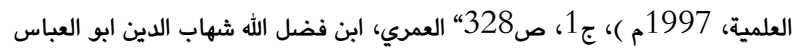
احمد بن يحيى، مسالك الابصار في ممالك الامصار ، تحقيق : حمزة احمد عباس، (

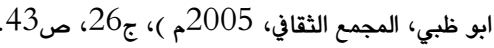

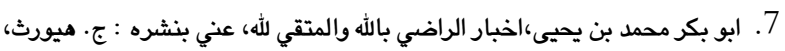
ط2، ( بيروت، دار الميسرة، 1983م )، ص234. 
الأسم الذي يطلق على الغجر أو النور في أسبانيا وهو خيتانو Jitanos أو في انكلترا

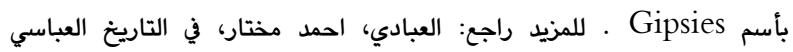

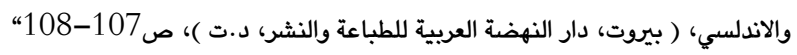

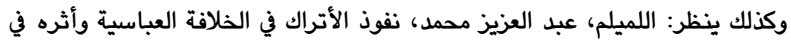

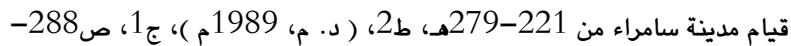

37. الطبري، تاريخ الطبري، ج9، ص8-8 و9" مسكويه، تجارب الامم، ج4،

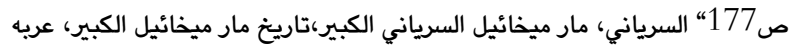

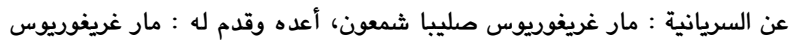

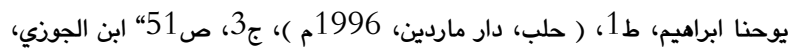

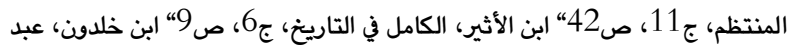

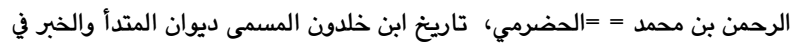

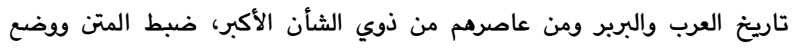

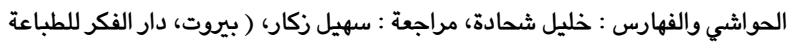

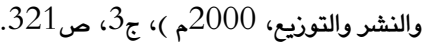

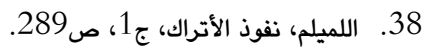

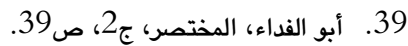

40. مؤيد الدولة ابو المظفر اسامة بن مرشد الكناني الشيزري ، كتاب الأعتبار،

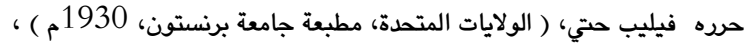

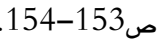

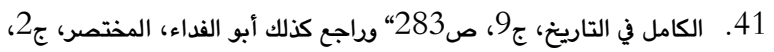
ص112. n

\section{5. مصادر ومراجع البحث}

\section{القرآن الكريم}

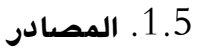

الأبشيهي: شهاب الدين محمد بن أحمد أبي الفتح ( ت 850هـ/ 1446م م )

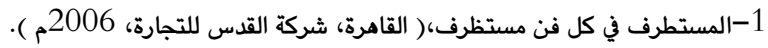

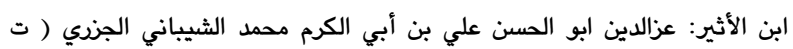

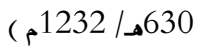
2-الكامل في التاريخ، حققه واعتنى به، عمر عبد السلام تدمري، ( بيروت، دار الكتاب العربي، 2010م ).

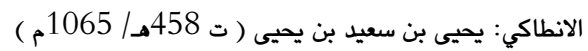
3-التاريخ الانطاكي، حققه ووضع فهارسه، عمر عبد السلام تدمري، ( لبنان،

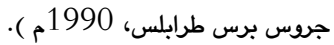

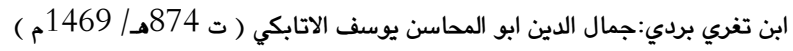

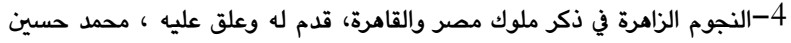

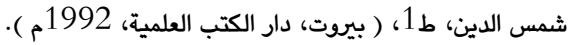

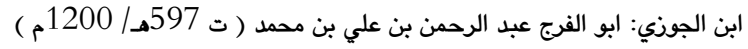

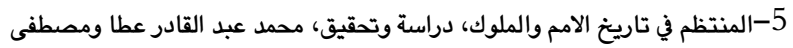

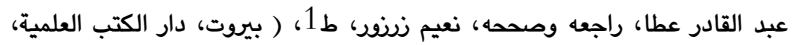
.) 1992

الحموي: ياقوت شهاب الدين ابو عبدالله بن عبدالله الرومي البغدادي ( ت 626هـ/ 1228 6-معجم البلدان،( بيروت، دار صادر، 1977م ) .

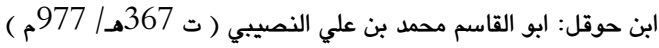
7-صورة الارض، ( ليدن، مطبعة بريل، 1938 193 م) ).
الله محمد بن احمد بن عثمان، العبر في خبر من غبر، حققها وضبطها: ابو هاجر محمد

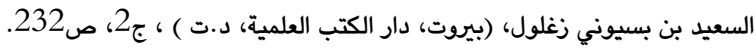

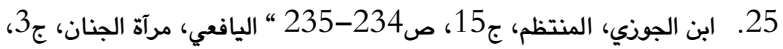

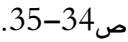

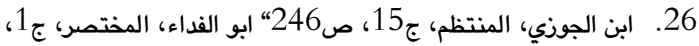

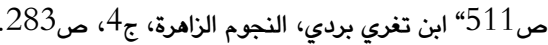

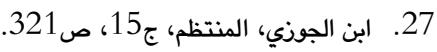

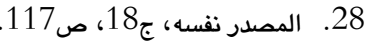

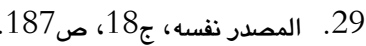

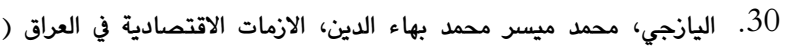

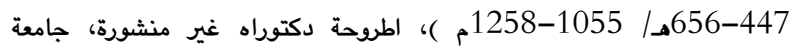

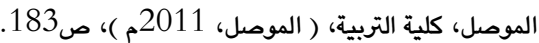

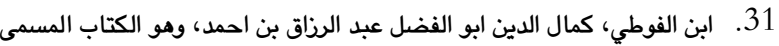

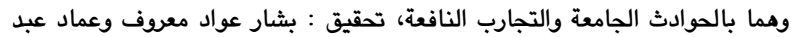

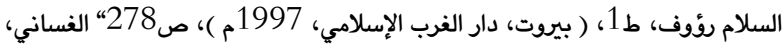
الملك الاشرف اسماعيل بن العباس،العسجد المسبوك والجوهر المحكوك في طبقات

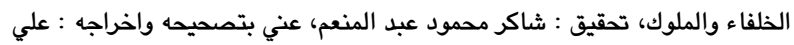

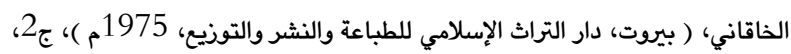
ص 32. ابو القاسم النصيبي، صورة الارض، ( ليدن، مطبعة بريل، 1938م )، ق2،

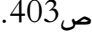

33. جور: مدينة نزهة طيبة بأقليم فارس بينها وبين شيراز عشرون فرسخاً (

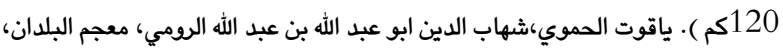

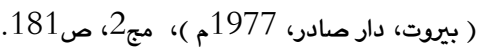
34. صورة الارض، ق2، صار صادر، 309-310.

أما الابشيهي فأشار الى بعض الأكراد الذين يقطعون الطريق ويعتصمون في الجبال

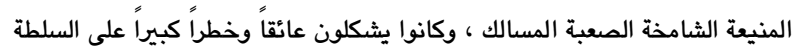
البويهية، فلما سمع الأمير البويهي عضد الدولة بخطر هؤلاء القوم من الأكراد أستعمل

حيلة للتخلص منهم والقضاء على نشاطهم وفي ذلك يقول :

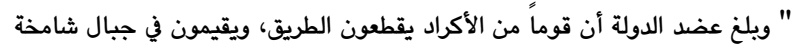

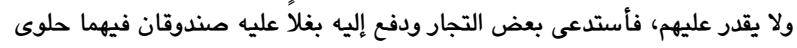

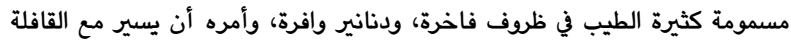

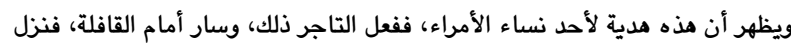

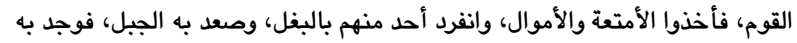

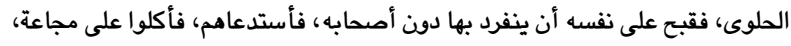

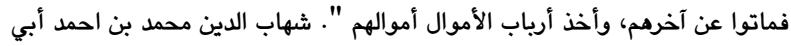

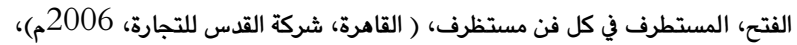
ص ص 429. ويبدو واضحاً عدم تعميم صاحب الخبر هذه الصفة على جميع افراد الشعب الكردي،

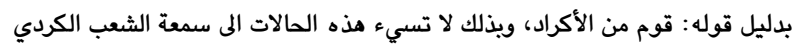

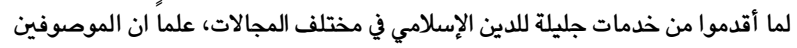
بالسرقة وقطع الطريق والى غير ذلك من الاعمال اللصوصية والتخريبية متواجدون ويكثرة لدى الامم والشعوب الاخرى.

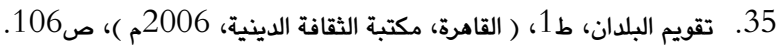

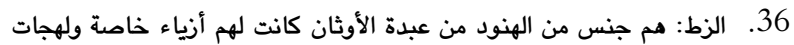

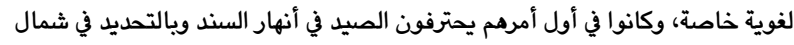

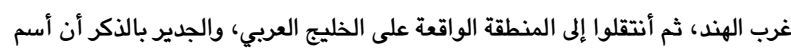

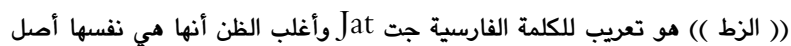


21-كتاب الاعتبار، حره فيليب حتي ؛( الولايات المتحدة، مطبعة جامعة برنستون،

النرخشي: ابو بكر محمد بن جعفر( ت 348هـ/ 959م ) 22-تاريخ بخارى، ترجمة عن الفارسية وعلق عليه ، امين عبد المجيد ونصر الله بـ الطرازي، ط33، ( القاهرة، مطبعة دار المعارف، د.ت ) ). الهمداني: محمد بن عبد الملك الفرضي ( ت 521هـ/ 23-تكملة تاريخ الطبري، تحقيق، البرت يوسف كنعان، ( بيروت، 1961م ). اليافعي : ابو محمد عبد الله بن اسعد بن علي بن سليمان اليمني المكي ( ت 768هـ (1366 24-مرآة الجنان وعبرة اليقضان في معرفة ما يعتبر من حوادث الزمان، وضع حواشيه، خليل منصور، ط1، ( بيروت، دار الكتب العلمية، 1997م معند ). 2.5 25-الدوري، عبد العزيز تاريخ العراق الاقتصادي في القرن الرابع الهجري، ط4، ( بيروت، مركز دراسات

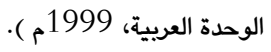
شريف: علي محمد 26-الحياة الاجتماعية في بلاد ما وراء النهر من القرن الرابع إلى نهاية القرن السادس

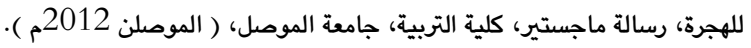
عارف: رفاه تقي الدين 27-العامة في بغداد في العصر العباسي الاول والثاني ( 132-334هـ/ 749946م )، مجلة جامعة بغداد، مج (7)، العدد (35). العبادي: الحمد مختار 28-في التاريخ العباسي والاندلسي، ( بيوت، دار النهضة العربية للطباعة والنشر،

فوزي: فاروق عمر 29-الخلافة العباسية السقوط والانهيار، ط1، ( عمان، دار الشروق للنشر والتوزيع، $\cdot($ م 1998

الكبيسي : حمدان عبد المجيد 30-اسواق بغداد حتى بداية العصر البويهي 145-334هـ/ 763-945م، )

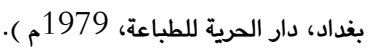
اللميلم : عبد العزيز محمد

31-نفوذ الأتراك في الخلافة العباسية وأثره في قيام مدينة سامراء من 221-

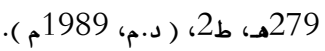
المسري : حسين علي 32-تجارة العراق في العصر العباسي، ( الكويت، ذات السلاسل، 1982م ).

$$
\text { النجار : محمد رجب }
$$

33-الشطار والعيارين حكايات في التراث العربي، سلسلة عالم المعرفة، ( الكويت، المجلس الوطني للثقافة والفنون والأدب، 1981م ). نوري : موفق سالم

34-اشكالية العلاقة بين العيارين والشطار والسلطة البويهية، مجلة المجمع العلمي

$$
\text { العراقي، مج (51)، ( بغداد، 2004م ). }
$$

35-الازمات الاقتصادية في العراق ( 656-447هـ/ى : 1055-1258م )، اطروحة الدين

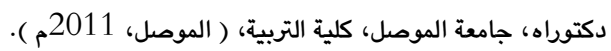

ابن خلدون، ابو زيد عبد الرحمن بن محمد الحضرمي ( ت 808هـ / 1405م )

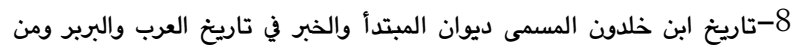
عاصرهم من ذوي الشأن الاكبر، ضبط المتن ووضع الحواسي والفهاس، خليل شحادة،

مراجة، سهيل زكار، ( بيوتق، دار الفكر للطباعة والنشر والتوزيع، 2000م ميع ). الذهبي: شمس الدين ابو عبد الله بن محمد بن احمد بن عثمان ( ت 748هـ (1347 9-العبر في خبر من غبر، حققها وضبطها ، ابو هاجر محمد سعيد بن بسيوني زغلول، ( بيروت، دار الكتب العلمية، د.ت ). الروذراودي: ابو شجاع محمد بن الحسين بن عبدالله ظهير الدين ( ت 488هـ / 1095)

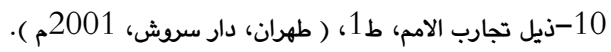

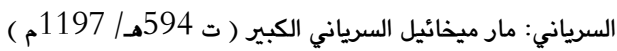
11-تاريخ مار ميخائيل الكبير،عريه عن السريانية، مار غريغوريوس صليبا شمعون، ط1، ( حلب، دار ماردين، 1996م ). الصابي: ابو الحسن الهلال بن المحسن بن ابراهيم ( ت 448هـ/ 1056م ماردين ) 12-كتاب التاريخ، الجزء الثامن، ( طهران، دار سروشن، د.ت ). الصولي: ابو بكر محمد بن يحيى ( ت 335هـ/ 946 م ) ) 13-اخبار الراضي بالله والمتقي الله ، عني بنشره ، ج. هيورث، ط2، بـ ( بيروت، دار

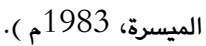
الطببي: ابو جعفر محمد بن جرير ( ت 3103ـ/ 922م ) 14- تاريخ الرسل والملوك،تحقيق، محمد ابو الفضل ابراهيم، ط3، ( القاهرة، دار

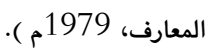
العمري: ابن فضل الله شهاب الدين ابو العباس احمد بن يحيى ( ت 749هـ/ (1348 15-مسالك الابصار في ممالك الامصار ، تحقيق، حمزة احمد عباس، ( ابو ظبي،

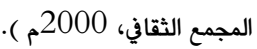
الغساني: الملك الاثرف عماد الدين ابو العباس اسماعيل بن العباس بن علي ( ت

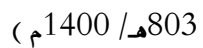
16- العسجد المسبوك والجوهر المحكوك في طبقات الخلفاء والملوك، تحقيق، شاكر محمود عبد المنعم، عني بتصحيحه واخراجه ، علي الخاقاني، ( بيروت، دار التراث الإسلامي للطباعة والنشر والتوزيع، 1975م محيد ). ابو الفداء: الملك المؤيد عماد الدين اسماعيل بن الملك الافضل نور الدين بن جمال

الدين محمود بن محمد بن عمر بن شاهنشاه بن ايوب ( ت 732هـ/ 1331م )

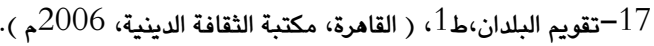
ابن الفوطي: ابو الفضل كمال الدين عبد الرزاق بن احمد البغدادي ( ت 723هـ/ (1323 18-الحوادث الجامعة والتجارب النافعة في المئة السابعة ( المنسوب )، تحقيق، بشار عواد معروف وعماد عبد السلام رؤف، ط1، ( بيروت، دار الغرب الإسلامي،

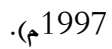
ابن كثير: عماد الدين ابو الفداء اسماعيل بن عمر القرثي الدمشقي ( 774هـ/ (1372 19-البداية والنهاية في التاريخ، اعتنى به ووثقها، عبد الرحمن اللادقي ومحمد غازي بيضون، ط5، ( بيووت، دار المعرفة، 1999م ). مسكويه : ابو علي احمد بن محمد بن يعقوب ( ت 421هـ/ بيروت دارئ 1030م )

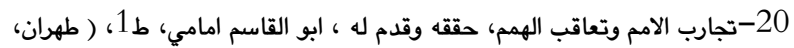
دار سروشن للطباعة والنشر، 1997م مارب ).

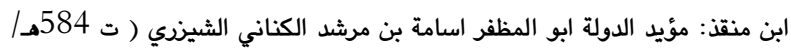
(188 
دزى وتالانكرن و كارتيكرنا ويَّ دراوهستاندنا ثيانا ئابووريدا ل بازيّريّن روزههلاتا ئيسلامى دا

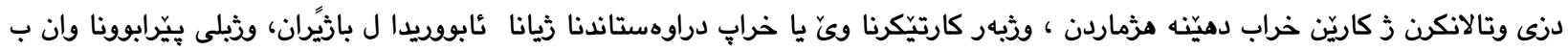

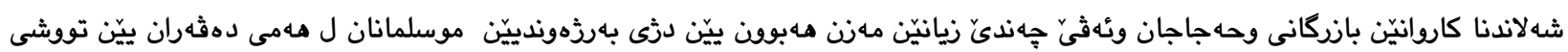
ثان جوّره كرياران دبن.

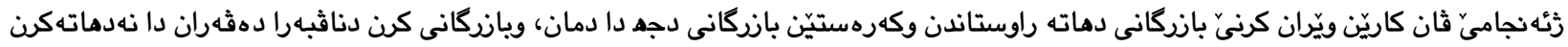

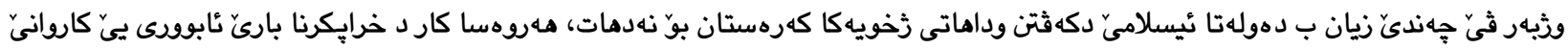

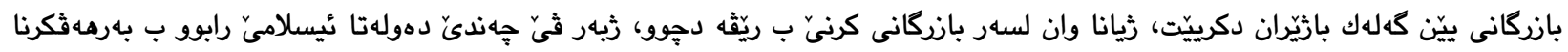

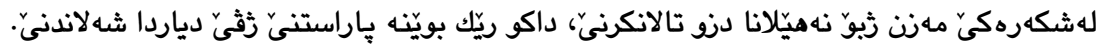

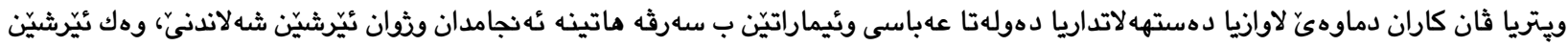
عهرهبان ( الاعراب ) لسهر كاروانان وئيّرشيّن ئهلزهت وئه لميد د دهريا مندى دا، دنو تالانكهران مفا ز كاروباريّن سياسى يِين دهولهت تيّدا

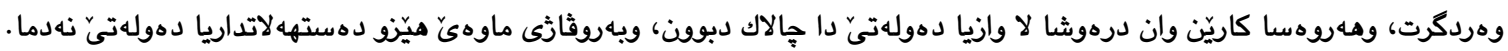

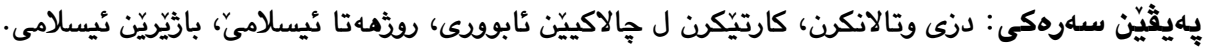

\title{
Thieves and Bandits and their Impact on Disrupting Economic Activities in the Islamic Mashreq Cities
}

\begin{abstract}
:
Acts of thieves and acts of banditry are considered the dirtiest acts deprived by God. As mentioned in the Holly Quran "as for the man or woman who is guilty of theft, recompense them by cutting off their hands for their crimes. that is the punishment from Allah. Allah is mighty, wise).38)". These acts affected the economy and trade of the cities as well as stealing the commercial caravans and pilgrim's caravans which affected Muslims 'interests in such areas. Because of such acts, importing and exporting of goods became more difficult to and from such areas. Moreover, taxes gained from trade were also affected by such acts. Since these theft acts affected the trade and economy of Islamic states in a bad way, Islamic states should have been ready to fight these thieves to secure commercial routes. The acts of thieves were more active during the weakness of the Abbasid state. Thieves usually make use of political circumstances to conduct their criminal acts. On the contrary, when the states are strong, they cannot conduct their criminal acts.

Keywords: Thieves and bandits, Impact on disrupting economic activities, Islamic mashreq Cities.
\end{abstract}

